\title{
UN ANÁLISIS SOBRE LA PARTICIPACIÓN EN EMPRENDIMIENTOS PRODUCTIVOS EN SALUD MENTAL EN EL MARCO DE LA ECONOMÍA SOCIAL EN CIUDAD DE BUENOS AIRES, ARGENTINA.
}

\author{
AN ANALYSIS ON PARTICIPATION IN PRODUCTIVE ENTERPRISES IN MENTAL HEALTH AREA, IN \\ THE CONTEXT OF SOCIAL ECONOMY IN BUENOS AIRES CITY- ARGENTINA.
}

\author{
María Esther Fernández, M. (1) Andrea Gaviglio, G. (2) Gabriela Adur, S. (3)
}

Revisión bibliográfica para la investigación: “Economía social y procesos educativos y de salud. Algunos estudios de casos de cooperación social"

\section{Resumen}

En este artículo nos proponemos realizar un análisis, desde una perspectiva centrada en la mirada de la Terapia Ocupacional, y recopilación de conceptos dados por autores de diferentes disciplinas (como economistas y antropólogos), con datos de observaciones realizadas en las visitas a La Huella. Este trabajo se realiza en el marco de la investigación: "Economía social y procesos educativos y de salud: algunos estudios de caso de cooperación social" de la Universidad Nacional de Quilmes. "La Huella" es una Empresa Social articulada al área de Salud Mental de la Ciudad de Buenos Aires en adelante Buenos. Aires.. Sus asociados trabajan en el sector de la Economía Social y Solidaria con una perspectiva de Comercio Justo cuya actividad básicamente, es la restauración y rediseño de muebles antiguos en desuso. Esta institución es uno de los emprendimientos seleccionado como muestra para el estudio de casos de esta Investigación. Este repaso por los distintos abordajes disciplinares nos permite justificar los cimientos y experiencias de trabajos basados en la cooperación, la suma de esfuerzos y el trabajo colectivo, y fundamentarlo hoy con una línea argumentativa bien defina por autores contemporáneos que explican el desarrollo y la instauración de la Economía Social y Solidaria como alternativa posible para la participación activa y digna de personas con trastornos mentales en emprendimientos productivos.

\section{Palabras clave}

Participación, ocupación, economía social y solidaria

\footnotetext{
1. Terapeuta Ocupacional, Universidad Nacional de Quilmes. Directora del Proyecto de Extensión Universitaria del Programa CREES-ICOTEA: INSYTU Juan B. Justo 3051 ed. 122 B- (C: P: 1879) Quilmes Oeste - Buenos Aires. Teléfonos: (54) 1142007098 celular: (54) 111562909270 Email: mefernan@unq.edu.ar

2. Licenciada en Terapia Ocupacional- Universidad Nacional de Quilmes.Maestra Especializada en Educación Primaria. IFD. $N^{\circ}$ 24. Docente de Psiquiatría en la carrera de Lic. en Terapia Ocupacional de la Universidad Nacional de Quilme. Maestrando en Salud Pública. UNLP.Directora del Proyecto de extensión Universitaria: SADIS (Servicio de Apoyo al Discapacitado).Calle 18 nº $^{\circ} 316$ (C.P. 1884) Berazategui. Telefonos: (54)114226-9065 celular: (54)11155144042 Email agaviglio@unq.edu.ar

3. Licenciada en Terapia Ocupacional- Universidad Nacional de Quilmes. Docente de la asignaturas Teoría de Terapia ocupación IV y asignaturas Practica Profesional I y Practica Profesional II

de en la carrera de Lic. en Terapia Ocupacional de la Universidad Nacional de Quilmes. Calle $203 \mathrm{~N}^{\circ} 375$ Berazategui. (CP 1889) Teléfonos: (54) 1143911296 - celular: (54)11 1561693425

gabiadur@hotmail.com
} 


\begin{abstract}
In this article we propose an analysis from a perspective focusing on the look of the occupational therapy, among a collection of concepts given by authors from different disciplines (such as economists and anthropologists), and data from observations made in visits to "La Huella" (the Footprint). "La Huella" is a Social Enterprise articulated to Mental health area of Buenos Aires city. Its partners working in the sector of Social and solidarity economy with a fair trade perspective. It's activity is basically the restoration and redesign of antique furniture in disuse.

This institution is one of the projects selected as a sample for the study of cases of research: Social Economy, Health and Educational processes: some case studies of social cooperation of Quilmes National University. This review by various disciplines approaches allows us justify the foundations of the work based on cooperation, the sum of efforts and collective work, and substantiate it today with an argumentative line well defined by contemporary authors to justify the development and the establishment of Social and solidarity economy as possible alternative for active participation and worthy of people with mental disorders in productive endeavors.
\end{abstract}

\title{
Key words
}

Participation, occupation, social and solidarity economy 


\section{INTRODUCCION:}

La Huella es una Empresa Social ${ }^{1}$, desde este espacio se promueve la inclusión social de personas en situación de vulnerabilidad socio laboral, impulsando la práctica autogestivas, el desarrollo de capacidades y la ciudadanía a través de la Economía Social y Solidaria (ESS). Es un proyecto colectivo que combina la Salud Comunitaria con la inclusión en el marco de Empresa Social. La Huella presenta un fuerte nexo con los procesos de salud, que permite vislumbrar y entender a la salud de manera integral, como un proceso social dinámico, vinculado al empoderamiento personal y grupal sobre un proceso social clave en la economía social y solidaria. Se evidencian las formas organizativas de trabajo asociativo y autogestivas.

En este escrito se analizan diferentes opiniones de autores de diversas disciplinas, que permiten generar nuevas concepciones sobre la visión de las personas con discapacidad en su entorno y en especial en relación al trabajo. Para realizar este análisis partimos de conceptos muy básicos y amplios que nos permitieron este acercamiento a las diferentes concepciones sobre las personas con discapacidad y el entrono. Por un lado tomamos las observaciones de Goffman²(1963), quien contribuye con el concepto de "estigmatizados", nombre que él de asigna a la visión y actitud que adopta la sociedad al referirse a este colectivo, y a partir de éste término desarrolla la temática, realizando una presentación de los sentimientos expuestos por personas en situación de vulnerabilidad, expone las experiencias de vida de sus entrevistados y comenta las diferentes situaciones de discriminación por las que ellos atraviesan en la constante búsqueda de oportunidades de empleo. Este autor comenta sobre las barreras que deben sortear las personas con discapacidad a la hora de manejarse en la comunidad, verificando que este aspecto les restringe el desenvolvimiento independiente en el desarrollo de su autonomía personal., finalmente hace referencia a las dificultades con las que se encuentra este colectivo, cuanto existe un mínimo de perspectiva para poder ascender dentro del ámbito laboral.

\footnotetext{
${ }^{1}$ A modo de consideraciones éticas: Los comentarios acerca de la empresa social La Huella, se realizan en función a una serie de visitas realizadas al lugar en caracter de conocimiento institucional, los datos aqui expuestos son de publico conocimiento, presenados en http://lahuellaemprendimientosocial.blogspot.com.ar/Los análisis e interpretaciones se realizan en el marco de la investigación: "Economía social y procesos educativos y de salud: algunos estudios de caso de cooperación social" de la Universidad Nacional de Quilmes. En este escrito no se presentan datos obtenidos de entrevistas a sus miembros. En breve se realizaran entrevistas pertinentes a esta y otras instituciones seleccionadas para esta Investigacion, para lo cual se contara con la existencia de consentimiento informado de los participantes como requisito indispensable para el desarrollo de esta investigación

2 Sociólogo y psicólogo, canadiense, cuenta con varios escritos relacionados con las vivencias de personas con discapacidad, en especial con las de salud mental, en este trabajo se toma especialmente el trabajo presentado en ESTIGMA, donde aborda diferentes tipos de discapacidades.
} 
Por otro lado se presentan los estudios realizados sobre "El fin de trabajo" de Neffa (2001), él aporta un importante análisis sobre la mirada de diversos autores, que hacen mención a diferentes alternativas interpretativas de la desocupación, captando la necesidad de la inclusión de los sectores vulnerables.

El termino de participación, se presenta desde el área de salud, de la Clasificación Internacional de las Funciones y la Discapacidad (CIF) ${ }^{3}$ de la Organización Mundial de la Salud (OMS) que describe al termino como: el acto de involucrarse en una situación vital y en un contexto con Factores ambientales, los cuales constituyen el ambiente físico, social y actitudinal en el que las personas viven y conducen sus vidas. Se relaciona este concepto con el marco teórico del Modelo de la ocupación Humana (Kielhofner, 2007) ${ }^{4}$ el termino "participación" se fundamenta sobre la base de lo que denominan "capacidad del desempeño" el cual se refiere a las habilidades físicas y mentales subyacentes y a la manera en que son utilizadas y percibidas durante el desempeño. Este modelo teórico, presta atención a la experiencias en el desempeño de las personas, para luego hablar de "participación ocupacional" el cual se refiere a la participación en actividades cotidianas, laborales y recreativas que forman parte del contexto socio cultural de la persona, y las cuales son deseadas o necesarias para su propio bienestar, durante el desempeño ocupacional, Kielhofner sostiene que realizamos determinadas acciones con propósito, donde la persona implementa habilidades para realizar las actividades., además señala a la experiencia del desempeño, y particularmente al hecho de tener limitaciones en el desempeño. Él Modelo sostiene que deberíamos al hecho de "prestar atención a la forma en que las personas perciben sus deficiencias, los profesionales pueden ayudar más a sus clientes". Otro termino interesante presenado por el Modelo es el de identidad ocupacional, esta seria generada por experiencias, es el sentido acumulado de lo que las personas son y desean llegar a ser como seres ocupacionales, alcanzar la adaptación ocupacional de las personas se refleja en la medida en que estas puedan crear y reproducir una identidad ocupacional positiva, y finalmente lograr la participación ocupacional, que implica: elegir/decidir, comprometerse, explorar, identificar, negociar, planificar, practicar, reevaluar, sostener".

El concepto de economía social y solidaria presenta varias fuentes de referencia, por ejemplo la Organización Internacional del Trabajo (OIT, 2010), que lo explica como: Un amplio conjunto de estrategias y herramientas para servir a las personas en su búsqueda de la justicia social a través del trabajo decente. Para la OIT "la economía social” está clásicamente asociada con las cooperativas, las organizaciones mutuales y las asociaciones. Estas instituciones comparten el objetivo de reunir a las organizaciones autónomas cuya meta es ofrecer un servicio a sus miembros o a la comunidad sin considerar las ganancias y que incorporan procesos democráticos de toma de decisiones a pesar de algunas diferencias en términos de la distribución de los beneficios, la economía social beneficia el

\footnotetext{
${ }^{3}$ Clasificación Internacional de las Funciones y la Discapacidad (CIF)

${ }^{4}$ Tomado del libro Williams \& Spackman (2011) 11 va. Edición, del capitulo Modelo de la Ocupación Humana.
} 
reconocimiento político y económico entre los ministerios y la administración y apoya las políticas públicas. La "economía solidaria" es un término especialmente utilizado en Francia, América Latina y Quebec. Claramente, el término expresa la solidaridad como el rasgo principal de este tipo de economía a diferencia de la economía capitalista convencional. En América Latina, este término se utiliza para cubrir una amplia gama de iniciativas. En otras regiones (Francia y Quebec), este término ha sido promovido para diferenciar los componentes establecidos de la economía social (por ejemplo, cooperativas, asociaciones, sociedades mutuales) y los mecanismos y organizaciones solidarios más recientes.

Tras las visitas realizadas a la Huella, y, a modo de aproximación argumentativa, podemos decir que sus asociados, se involucran en una situación vital, se comprometen, negocian, planifican y sostienen una actividad, generando una participación positiva en el emprendimiento, se observa que a lo largo de los años han logrado una evolución positiva. Los miembros de "la Huella" demuestran en su diario desempeño que poseen las competencias necesarias para enfrentar un mercado cada vez más exigente, en cantidad de producción y en calidad de producto. Actualmente se encuentran en formación para fortalecer esta meta., para lo cual articulan acciones con otras instituciones, como Universidades, centros de formación profesional, capacitación interna, y otras a fin de mejorar la calidad del servicio, aumentar y acceder a nuevos nichos de ventas. Los miembros de La Huella aspiran a encontrar la estrategia más conveniente para el crecimiento empresarial.

Consideramos que un componente necesario que lleva a la participación activa del individuo, a comprometerse y sostener un emprendimiento, es el sentido de pertenencia, el hecho de sentirse dueños de un proyecto común., así lo asegura la OIT (2011), al hacer referencia a los emprendimientos de ESS, destaca la importancia del sentimiento de "empoderamiento", sostiene que es un factor importante que permite a los individuos y las comunidades tener voz y poder ser representados. El empoderamiento puede crearse a través de una variedad de procesos y mecanismos. Los miembros y usuarios ganan empoderamiento a través de su participación activa en el proceso participativo de toma de decisiones dentro de la organización y fuera de las organizaciones cuando están negociando con interlocutores externos. A escala colectiva, las organizaciones de Economía Social y Solidaria (OESS) también contribuyen al proceso de empoderamiento de los individuos y las comunidades demostrando que todos los individuos pueden convertirse en interlocutores económicos y sociales activos y productivos.

Este proceso de empoderamiento, es el proceso en el cual los sujetos avanzan en la medida que logran tomar conciencia de sus posibilidades, aumentan la capacidad de decisión y ganan confianza en sí mismos. En el caso de la cooperación social este empoderamiento tiene una relación recíproca con la actividad y con organización que ésta implica, por lo tanto todo sujeto con una ampliación de su autoestima, con capacidades desarrolladas y seguro de sí mismo puede contribuir y participar de forma más activa a la acción colectiva. De la misma manera la acción colectiva permite que los sujetos tengan mejor acceso a los 
servicios y mayor difusión de la información, incidiendo así en el empoderamiento individual.

La Huella, es un reflejo de generación de oportunidades, de cooperación social, de la NO limitación por la condición de enfermedad. Para justificar esta afirmación acercamos el trabajo presentado por Frank Kronemberg ${ }^{5}$ (2006), en el que hace referencia a una persona ciega, en este trabajo ellos no tienen en cuenta el tipo de discapacidad, sino como una persona con discapacidad atraviesa las etapas de la vida, superando obstáculos y alcanzando autonomía y ciudadanía. El autor incita a los Terapistas Ocupacionales, a procurar una mirada más amplia en relación a las posibilidades y oportunidades que les brindan a sus clientes, este caso nos intima a ver más allá de las competencias visibles de una persona con discapacidad. Es de público conocimiento que en la sociedad actual las personas con discapacidad presentan dificultades y restricciones a lo largo de su formación educativa y en las diferentes áreas de sus vidas. En la Huella se refleja la posibilidad de hacer efectivos los derechos de las personas con discapacidad o en sitaucion de vulnerabilidad social, se trabaja y habla sobre las limitaciones que les impone la sociedad, y se sostiene la importancia testificar sobre el respeto a los derechos y ser tratados y consideramos de la misma manera que el resto de las personas: El autor enmarca este caso de discapcidad bajo el nombre de "sin fronteras" por dos motivos: por un lado quiere decir, que en cualquier lugar del mundo las personas ciegas pueden ser preparadas para una vida autoderminada e independiente, y por otro lado se relaciona con el no querer poner fronteras o límites a las personas ciegas. Consideramos abierta a otras personas con discapacidad esta forma en que el autor se plantea la discpacidad, la consideramos extensiva y con posibilidad de proyectarla a cualquier tipo de discapacidad y limitaicones. El autor concluye afirmando que: "solo aquellos que tenga acceso a la información podrán llevar control de sus vidas., pero que más importante aun que las técnicas y el conocimiento, es la transmisión de la confianza en uno mismo, la base para no sentir vergüenza por ser ciego, para ser audaz y firme en la lucha contra la exclusión de nuestra sociedad obsesionada con la eficiencia". Consideramos en la Huella sus asociados, talleristas y coordinadores se encuentran en capacitación permanente a fin de nivelar con las exigencias del mercado, imponerse en el mercado buscando estrategias de y puntos de venta. En este emprendimiento se busca la autogestión de una vida social, fundamentado en la solidaridad, el reconocimiento de competencias ente sus miembros asociados, ellos hacen frente a la exclusión y podemos decir que hoy a nivel social han logrado la construcción de una identidad, esta empresa social alcanza este perfil de espacio inclusivo, en cuanto a que como lugar de trabajo no limita las expectativas de sus miembros.

\footnotetext{
${ }^{5}$ del libro "Terapia Ocupacional sin fronteras" en el capitulo "el derecho a ser ciego sin ser discapacitado" pág. 37-41
} 


\section{Análisis de diferentes disciplinas y su relación con la economía social y la salud mental}

Después de haber revisado los conceptos de participación, ocupación y el de economía social y solidaria, y después de ésta presentación general de la La Huella, en la que señalamos básicamente los aspectos relacionados con el trabajo, para conocer sobre la ocupación de sus asociados y sobre sus metas como emprendimiento social, comenzamos con nuestro análisis de opiniones de autores de diversas disciplinas sobre la participación de personas en situación de vulnerabilidad social en emprendimientos relacionados con la Economía social y las analogías con la Huella.

Karl Marx ${ }^{6}$ (1885), desde sus principios presenta al trabajo grupal como fuente de rendimiento y eficacia en la producción industrial, tanto a nivel personal como a nivel de producción grupal, identifica la valoración de las competencias, la suma de esfuerzos hacia una misma meta, la fuerza combinada como clave, llevando al lector a entender la cooperación en el trabajador colectivo. Para fundamentar este análisis, se toman palabras textuales de Marx, del libro El Capital, en el que se explaya sobre el concepto de cooperación (1885, cap. XI), en este capítulo se hace referencia a los trabajos que implican esfuerzos, y sostiene que : "El efecto del trabajo combinado, en tales casos, no podría lograrlo el trabajo de individuos aislados, o solo podría alcanzarlo en espacios de tiempo mucho más prolongados, o solo en una escala ínfima" dice también: "No se trata aquí únicamente de un aumento de la fuerza productiva individual, debido a la cooperación, sino de la creación de una fuerza productiva que en sí y para sí es forzoso que sea una fuerza de masas".

Al relacionar lo supuesto por Marx con una jornada de rutina laboral en La Huella, podemos decir que el trabajo colectivo, colaborativo y asociativo son el estandarte los que caracteriza y que lo conforma y sostiene como Empresa Social. Cuando llega un pedido de trabajo (restauración de muebles) cada uno de sus miembros sabe lo que tiene y puede hacer él y también sus compañeros, cada uno hace y colabora, se observa el reconocimiento de saberes entre sus miembros, con lo cual las competencias de cada uno suman a la hora de empezar a trabajar, las habilidades individuales construyen un proyecto común, potencian la asociatividad como estrategia de trabajo.

Sobre esta base, se presentan autores contemporáneos que nos permiten conllevar a un análisis sobre la participación de miembros de emprendimientos productivos en contextos de salud Mental dentro del marco de la economía social y solidaria. Se ofrece entonces la siguiente selección:

\footnotetext{
${ }^{6}$ A modo de introducción y para elaborar un marco de referencia de base, tomamos a Karl Marx (1867). Recurrimos a varios capítulos de versiones reeditadas para tomar algunos conceptos de su perfil ideológico, luego sí presentamos algunas líneas textuales de diferentes capítulos.
} 
- $\quad$ Gonzalo Vázquez ${ }^{7}$ (2010), hace referencia a las conclusiones del investigador Gaiger y coincide al igual que nosotros en que en la Huella la auto convocatoria a la asociación y la motivación constante a mantener y fortalecer el grupo el trabajo es un trabajo en equipo, él dice que la distancia actual entre estas exigencias y la realidad es enorme, y plantea la necesidad de promover activamente el desarrollo de esta capacidad emprendedora, porque estima que no se generará espontáneamente. Para ello, Gaiger (2006) afirma que es fundamental conocer y saber aprovechar "las virtudes de la comunidad de trabajo", explotar el potencial productivo del trabajo asociativo y autogestionado, de manera que se pueda plasmar este potencial en resultados económicos concretos. Sintéticamente, este autor sostiene que: la cooperación en el trabajo multiplica la capacidad individual de cada trabajador; las decisiones colectivas conducen a resultados más eficientes; compartir conocimientos e información estimula la innovación y reduce costos de transacción; la confianza y el sentido de pertenencia a un proyecto común estimulan y motivan adicionalmente. En la Huella la actitud de cooperación es una constante, las funciones propias de la jornada como resolución de problemas, asumir decisiones comunes lleva al hecho de fortalecer sus vínculos permite un aumento de confianza en sí mismo y una autogestión de una vida social inclusiva, y por supuesto una participación ocupacional.

- $\quad$ Goffman ${ }^{8}(1998)$ en su libro Estigmas, utiliza el término de status social y lo modifica por el de identidad social, al cual se le asignan atributos personales como la honestidad, estructurales y también la ocupación. Cuando los atributos lo vuelven diferente a los demás, y lo convierte en alguien menos preciable -malvado, peligrosa o débil, a veces también recibe el nombre de defecto, falla o desventaja. Un atributo de esta naturaleza es un "estigma". Un estigma es una clase especial de relación entre atributo y estereotipo. El individuo estigmatizado tiende a sostener las mismas creencias sobre la identidad que nosotros; este es un hecho fundamental. La sensación de ser una "una persona normal" un ser humano como cualquier otro, un individuo que por consiguiente, merece una oportunidad justa para iniciarse en una actividad, puede ser uno de sus más profundos sentimientos acerca de su identidad. En su libro Gofman trata las relaciones mixtas entre estigmatizados y normales, los momentos en los que se hallan en una misma "situación social". El individuo estigmatizado puede descubrir que se siente inseguro acerca del modo en que nosotros los normales, vamos a identificarlo y a recibirlo. La incertidumbre del estigmatizado surge no solo porque ignora en que categoría será ubicado, sino también, si la ubicación lo favorece, porque sabe que en su fuero interno los demás pueden definirlo en función de su estigma (8). Los miembros de la Huella han percibido a lo largo de sus vidas esta presión de la sociedad al hacer referencia sobre su condición de ser pacientes de un hospital Psiquiátrico, acceder a un trabajo se hace difícil para ellos, cuando hay una historia clínica que traduce su residencia y años de tratamiento, ellos hoy no manifiestan

\footnotetext{
${ }^{7}$ Economista (UBA), en su presentación sobre sostenibilidad de emprendimientos auto gestionados (2010) en la revista de ciencias sociales segunda época de la Universidad nacional de Quilmes.

${ }^{8}$ (2006) Goffman analiza las diferentes situación de las personas que social e históricamente son etiquetados por el estigma social y los mecanismos de aceptación y exclusión a los que están sometidos.
} 
inseguridad de decir quiénes son y cómo trabajan, al contrario descubrieron y defiende la situación de estar asociados y conformar un emprendimiento de trabajo.

- $\quad$ Bialakowsky Alberto y colaboradores $(2001)^{9}$, en estudios sobre la población en situación de vulnerabilidad socio-laboral desocupada, develan el sufrimiento como producido y productor de procesos sociales de trabajo, en el proceso de esta investigación vislumbran un reconocimiento subjetivo y otro reconocimiento social al respecto. Estos autores califican el proceso social de trabajo que lleva a la exclusión delineando un recorrido, como metáfora constructiva, en el que se profundiza el análisis de la construcción de la segregación (material, simbólica) y de la interioridad entendidas en tres movimientos: la muralidad (separación, compuesta por ladrillos como la demarcación, la grupalidad y la pertenencia, y los códigos de silencio) interioridad en si (el hogar, la vivienda y las instituciones como las salas de salud que se enlazan con los microsistema) y la implosión (relaciones violentas que se instalan en los contextos, que luchan por los espacios por imponer su voluntad o simplemente por sobrevivir a la lógica excluidora del sistema, contribuye a la fragmentación familiar e institucional). Como propuesta Bialakowsky sugiere "la conformación de colectivos, con una mirada holística e integrada en los problemas que se deben enfrentar". La experiencia practica nos lleva a reflexionar sobre la situación de personas en tratamientos psiquiátricos internalizados, tal cual lo aseguran estos autores, las personas internadas en neuropsiquiatricos manifiestan los síntomas y signos a los que estos autores denominan "la muralidad" esta barrera que los separa de situaciones de vida real, que los encierra en el ambiente hospitalario, que no deja de ser excluyente en estas instancias. Los miembros de La huella hoy se consideran trabajadores, incluidos en un sistema, comparten un lugar de trabajo con derechos y responsabilidades, es un espacio que permite compartir historias familiares, necesidades personales, problemas de la calle, obstáculos del diario vivir en una sociedad común a la de todos, sin diferencias, ni condiciones especiales, sin muros.

Bialkowsky, acuerda y hace referencia a Goffman, afirmando que..."Es similar para quienes están o estuvieron relacionados con una institución manicomial o una cárcel: el traspasar sus puertas implica enfrentarse al estigma de la locura o de la delincuencia cada vez que buscan empleo o su relación con otro que conoce su historia" y también ambos sostienen que: "el ex enfermo mental como un habitante de un núcleo urbano segregado, debe "ocultar información sobre su identidad social real, recibiendo y aceptando un trato basado en suposiciones respecto de su persona, deteriorando su identidad" por esto la dificultad de acceder a un trabajo y hablar sobre su historia laboral". Los asociados de la Huella no tienen nada que ocultar, han alcanzado una identidad social, su participación en este

\footnotetext{
${ }^{9}$ Bialakowsky y col. presentan este escrito en la Revista Herramienta, donde plantean diversos interrogantes e hipótesis de de investigación e intervención sobre los padecimientos relacionados con los cambios socio-económicos actuales. en el "proceso de trabajo y padecimiento en la exclusión social" sobre estudios de casos realizados en los barrios Carlos Gardel y Ejercito de los Andes de la ciudad de Buenos Aires, él a través de un análisis sobre el discurso de los protagonista de su investigación,
} 
emprendimiento de trabajo los estimula a comprometerse día a día con su grupo de trabajo, se observa superada la utopía de acceder a una ocupación digna, y conformar hoy la clase trabajadora.

Para nosotros la Huella es parte de esta ESS, hoy hace frente a la pobreza, atraviesa muros socialmente instaurados y permite la inclusión en una sociedad excluyente, hoy La Huella reinventa la realidad, se evidencia la asociacion colaborativa en la resolución de las necesidades de todos. La nueva ley de salud mental ${ }^{i}$ argentina fomenta el derecho a recibir una justa compensación por la tarea en caso de participar de actividades encuadradas como laborterapia o trabajos comunitarios, que impliquen producción de objetos, obras o servicios que luego sean comercializados, como también sostiene la promoción y prevención de la salud mediante la implementación de diferentes servicios entre ellos "emprendimientos sociales", consideramos que la Huella es una alternativa acertada y desarrollada dentro del marco sugerido por esta ley. Ademas traemos a colacion lo sugerido por la convención internacional de los derechos de la personas con discapacidad, en la que se asegura que "trabajar incluye el derecho a tener la oportunidad de ganarse la vida mediante un trabajo libremente elegido o aceptado en un mercado y un entorno laborales que sean abiertos, inclusivos y Accesibles a las personas con discapacidad". Consideramos que dentro del marco legal de la Salud Mental, La Huella reúnen las características propias de un tratamiento psicosocial acertado y positivo, y que hoy exterioriza en su trayectoria como grupo de trabajo gestionado dentro del marco de la ESS.

La Huella en sus hechos demuestra como resultado expuesto la calidad de producto terminado. Podemos decir que es un colectivo auto convocado, auto gestionado y autosuficiente.

- $\quad \mathrm{Neffa}^{10}$, en su presentación sobre "El fin del trabajo", cita y comenta las conclusiones de varios autores, para este análisis, tomamos sólo aquellos que consideramos que vinculan a la ESS con situaciones similares a las vivenciadas en la Huella, y recurrimos a estas 5 citas de Neffa según:

I) Jeremy Rifkin (economista estadounidense), quien por un lado sostiene que es un aliciente la generación y desarrollo de la economía social, y es una solucion para reducir el desempleo, afirma que es la constitución formal de un tercer sector, de economía social, cuyos actores principales serian las ONG., quienes administrarían mas honestamente los recursos y así la mayor parte de los subsidios recibidos del sector publico llegarían directamente a los mas necesitados, sobre un trabajo voluntario y que procure generar

\footnotetext{
${ }^{10}$ En este escrito Neffa y cols, realizan una argumentación sobre el fin de trabajo, determinando 4 líneas para agrupar las distintas opiniones de autores: 1) el auge de la economía de servicios, donde se observa una mayor heterogeneidad marcando diferenciación en las relaciones laborales entre trabajadores calificados y precariedad laboral 2) el trabajo deja de ser el criterio de ubicación social. 3) perdida del trabajo como generador de valor 4) el poder político, los trabajadores pierden el valor en función a capitalistas o rentistas.
} 
empleos que requieran una baja dotación de capital y donde los salarios sean acorde a un mínimo de subsistencia.

El autor afirma que de todas maneras sería mejor que estar desempleados y no tener ningún ingreso. Acordamos en que la ES es una de las grandes soluciones, pero no consideramos que antes que nada estaría bien recibir un subsidio del estado. No creemos conveniente limitar los ingresos generados por un emprendimiento ni mucho menos encapsular en este concepto a los emprendimientos sociales subsidiados por el estado. Riffkin no recupera el valor de la ocupación significativa, como lo vemos en La Huella, del reconcomiendo de la competencia y del sentido de empoderamiento que se genera en los emprendimientos sociales cuando sus miembros lo consideran una opción de trabajo digno y como él lo sostiene una solución para reducir el desempleo.

II) Claus Offe (político y sociólogo), sobre el desempleo y la insatisfacción que esta carencia provoca en la sociedad, sostiene que actualmente existe una erosión de los fundamentos culturales y políticos de una identidad colectiva centrada en el trabajo, y que "a medida que aumentan las experiencias (o la anticipación) del desempleo, o en su caso la salida no voluntaria de la vida económica activa, se incrementa el efecto estigmatizador y auto estigmatizador del desempleo, puesto que, aunque solo apareciera concentrado en determinadas ramas de la actividad económica, el paro (el desempleo) por lo general es imputado a un fracaso o culpa individual”.

Para Offe "el impacto del desempleo recae sobre la subjetividad, pues esta situación afecta la identidad y el sentido de pertenencia". En la Huella sus asociados hablan de construcción de identidad, de empoderamietno y de sentido de pertenencia en cada trabajo que se realiza, en cada decisión que se asume y en cada problema a solucionar, no se habla de empleo ni de desempleo, se habla de una ocupación significativa, conformando parte de la activa de la clase trabajadora.

III) Francois Gaudu, propone para esta población implementar un cambio que consiste en pasar de contrato de trabajo a estatuto, esta podría ser una alternativa positiva para las personas con enfermedades mentales, a fin de mantener su relación de trabajo mientras se encuentra en tratamiento, por episodios de brotes o efectos de medicación. Él propone inventar una nueva modalidad de relación salarial, el estatuto, que establece una relación laboral de esos individuos desocupados con la sociedad en su conjunto y no con una empresa en particular, pero que de cualquier manera establece mutuas obligaciones y derechos, incluso durante períodos de inactividad que transcurre entre dos empleos hasta el momento de la inserción en un "empleo verdadero".

Consideramos que la propuesta de Gaudu es alternativa viable, si la persona se encuentra empleada y se le consideran las situaciones especiales de su tratamiento y los episodios de su enfermedad, siempre y cuando se mantengan las condiciones de empleo hasta lograr su jubliacion por desempeño y no por discapacidad. Seria una colaboracion y una respuesta sustancial por parte del estado garantizarle a los asociados de la Huella un estatuto de 
trabajo, a modo de considerar sus aptitudes y competnecias de trabajdores independientes, ellos actualmente trabajan por pedido y solo acceden a los recusos económicos que pueden autogestionarse, sin percibir otro ingreso, esta situación se agudiza en los episodios de enfemedad.

IV) Centre Des Jeunes Dirigeants d'Entreprises (CJD), J.L. Laville, Jean Roustang y Alain Lipitiez, presentan la opción de "apoyar la economía plural para posibilitar la plena actividad y crear y consolidar el tercer sector o sector de la economía social, significa aumentar las actividades que pueden proporcionar una utilidad social" entre ellos Lipitiez, comenta que los trabajadores que ocuparían esos puestos no estarían directamente a cargo del sector público, sino de organizaciones de tipo asociativo de ONG, que harían menos directas las relaciones del trabajador con el empleador público o privado, actuando este por intermedio de asociaciones. Esta propuesta se trataría de una estratificación, un sector de economía solidaria, donde el trabajo proporciona un ingreso, un estatuto permite realizar actividades socialmente útiles, tanto productivas de bienes como prestadoras de servicios, pero como un criterio de rentabilidad diferente. Laville no habla explícitamente del fin del trabajo, sino de la redefinición de las formas que adopta el trabajo y propone que definan otras actividades, que sin ser propiamente empleos, puedan ser valorizadas socialmente".

En la Huella existe el reconomiento social sobre el tipo de trabjao que se raliza allí, la restauración de muebles, muchas veces se realiza sobre muebles en desuso donados por Organismos Publicos (escasas veces por cuestiones burocraticas) y por vecino y/o conocidos que saben del trabajo, otros solicitan el servicio de retapizado, o reparación de muebles. La opinión de este equipo de investigadores franceses permite pensar en emprendimientos productivos que garanticen un mayor grado de sustentabilidad y sostenibilidad., lo cual es factible de lograr con el apoyo de Instituciones que acompañen el desarrollo y crecimiento de emprendiemitnos, tales como Universidades comprometidas con la problemática, como servicios médicos que se involucren con las Organizaciones comunitarias. Tal cual lo asegura luego Neffa a modo de comentario personal, sostiene que algunos de estos autores proponen un ingreso mínimo incondicional para evitar la exclusión social y la emergencia de una esfera de producción de bienes y servicios sociales con valor de uso, asignando una gran importancia a las asociaciones civiles sin fines de lucro, donde trabajarían personas benévolas junto con asalariados profesionales, todos ellos encuadrados en un mismo convenio colectivo. Además agrega que estas asociaciones deberían complementarse entre si y competir con el estado y con el mercado. Este nuevo sector social debería ser una estructura horizontal, para que este tipo de empleo se genere en todos lo sectores. Hoy la Huella cuenta con el apoyo de varias organizaciones comunitarias que favorecen su autosostenimiento, sus mismos miembros se reconocen parte de un todo y se incluyen en las redes que se van formando en este proceso de inclusión.

V) Para Supiot el estado debe continuar existiendo, para fijar un marco jurídico, sin el cual el orden económico y social no podrían existir, además propone que se utilice el concepto de "ciudadanía social" más que el de "protección social" para sintetizar los 
objetivos actuales del derecho del trabajo y del derecho social, porque el concepto de ciudadanía supone dentro de las empresas la activa participación de las personas involucradas en la definición, en la puesta en práctica y la evaluación de sus derechos".

Conasideramos que este autor se acerca al concepto de el derecho a acceder a un trabajo genuino, a realizar esta proyección de sentirse parte de un sistema que deberiae star plnaificado para todos y a sentirse y verse como parte del mismo.,

- $\quad$ El Terapista Ocupacional Frank Kronenberg $(2011)^{11}$, comenta su positiva experiencia en emprendimientos sociales desarrollados en África como: 'Ama Job Job, 'Sensory Intelligence', 'Baby \& Toddler Sense, entre otros. En otro espacio de la entrevista se le pregunta sobre trabajos dignos de ser reconocidos, y al respecto él menciona los realizado en Argentina, comentando las iniciativas artesanales del Proyecto Isole en el servicio de Terapia ocupacional del Hospital Municipal "José Tiburcio Borda" (papel reciclado, agendas y lámparas $Y$ restauración y re-diseño de muebles.

- $\quad$ Alejandro Rofman ${ }^{12}$ (2010), sostiene que la economía solidaria es el modelo de organización de la sociedad que incluye todas las manifestaciones productivas de bienes y servicios que se rigen por un principio fundamental: el desarrollar su actividad con la finalidad de mejorar la calidad de vida de quienes toman parte en las mismas. Las consideraciones de Rofman son elocuentes y certeras, al relacionarlo con las situaciones que han conllevado a La Huella a conformarse como Organización, hoy sus trabajadores son porpietarios, ellos son los dueños del capital que operan, y cuentan con un poderoso capital, el que esta conformado por los valores de la solidaridad y de la cooperación, estas hoy son sus herramientas indispensables de trabajo, estas les han permitivo organizarse y hoy sentirse parte de la clase trabajdora.

\section{CONCLUSIÓN:}

Desde una mirada de Terapia Ocupacional revalidamos que el apoyo al crecimiento de los emprendimientos productivos en el marco de una economía social y solidaria es una alternativa positiva para la inclusión social y laboral de las personas que padecen trastornos mentales.

De acuerdo a la bibliografía consultada, se observa que es común a esta población la perdida y la insostenibilidad de un empleo, como también la falta de oportunidades para ingresar al mercado de trabajo. Podemos decir, que en este colectivo el desempleo, es un factor común en sus historias de vida personal, se vislumbra la dificultad para poder

\footnotetext{
${ }^{11} \mathrm{~F}$. Kronenberg es Mg. y Terapista Ocupacional, se presentan comentarios ofrecidos en una entrevista que le realiza la asociación de Terapia Ocupacional Argentina, lo expone en su web.

${ }^{12}$ Lo presenta en la revista de ciencias sociales, segunda época, en el capitulo "la economía solidaria y los desafíos actuales"
} 
integrase al ámbito laboral competitivo y las restricciones para sostener y/o reintegrarse a su habitual trabajo. En la Huella se observa el compromiso con el trabajo, asistencia y rutina laboral, organización y proyección a acciones futuras en pos al crecimiento grupal con un fin económico y social.

Las sugerencias presentadas por los autores seleccionados precedentemente son viables de aplicación, dentro del marco de la Economía Social y Solidaria. Consideramos factible la conformación de emprendimientos productivos fomentando la auto convocatoria y auto agrupación con apoyo profesional en la medida en que estos la necesiten. La nueva ley de salud mental, en sus artículos 7,9 y 11 presentan como tratamiento, la rehabilitación basada en la comunidad, aconsejando el fortalecimiento de lazos sociales, la participación activa de esta población, en ocupaciones como cooperativas de trabajo, centros de capacitación socio-laboral y emprendimientos sociales. Sostenemos que dentro del marco de la ESS se puede alcanzar la participación y construir una identidad ocupacional, valorando las experiencias acumuladas, y permitiendo la proyección de lo que las personas son y desean llegar a ser como seres ocupacionales.

Creemos que este análisis puede ser un material interesante de tener en cuenta a la hora de fundamentar el marco de la ESS como estrategia para el desarrollo de emprendiemientos sociales. Los datos de experiencias relevantes, junto con el aval teórico, podría ser un tema de agenda para las políticas públicas, a fin de maximizar la continuidad de estas iniciativas y alcanzar un mayor promoción de las mismas, siempre y cuando se disponga del apoyo logístico necesario para su desarrollo. Estos emprendimientos productivos, pueden ubicarse por dentro y por fuera de los contextos de salud, como en las Asaciones y Organizaciones barriales, con el compromiso y el apoyo del Estado y sobre todo con nuestro acompañamiento técnico y humano desde las Instituciones Educativas como las Universidades, incitando a sus asociados y colaboradores a sentirnos parte, a involucrarnos con el emprendimiento y a permitirnos una participación ocupacional en una economía social y solidaria activa para todos.

\section{REFERENCIAS BIBLIOGRAFICAS:}

Bialakowsky A. y Col. (2001) "Proceso de trabajo y padecimiento en la exclusión social”. En Revista Herramienta. Buenos Aires.;: 15:67-89

CONVENCIÓN SOBRE LOS DERECHOS DE LAS PERSONAS CON DISCAPACIDAD - 2006 (consultada 25/10/12) http://www.un.org/spanish/disabilities/convention/qanda.htm

Goffman, E. (2006) ESTIGMA. La identidad deteriorada. 10ma reimpresión. Ed. Amorroutu editores. Buenos aires. Madrid 
Kielhofner, G. (2011) “El modelo de la ocupación humana”, En Terapia Ocupacional Willard y Spackman. $11^{\circ}$ edición. Buenos Aires: Ed. Medica PANAMERICANA.; 44: 446-461

Kronenberg, F. (2011) en Entrevista realizada por la AATO. a Ciudad del Cabo. Sudáfrica. Disponible en: http://socialeconomy.itcilo.org/ssea-reader2011-spanish-web.pdf (Consultado: 26/3/2012)

Kronenberg, F. (2006) Tenberken "El derecho a ser ciego sin ser discapacitado" En Terapia ocupacional sin fronteras, Ed.Panamericana.,; 3: 31- 39

Ley Nacional 26657 (2010). Salud mental. Derecho a la protección de la salud mental. Consultado: 26/04/2012. :http://test.e-legisar.msal.gov.ar/leisref/public/showAct.php?id=16773\&word)

Marx, K. (1999) “Cooperación” “En El capital. México: Ed. Siglo XXI; 11:391 - 408; 12: División del trabajo y manufactura" 12: 409 - 449 y "maquinaria y gran industria", punto 4 "la fabrica" 13: 511 - 521

Neffa, J. (2001) "Presentación del debate reciente sobre el fin del trabajo", En El futuro del trabajo el trabajo del futuro. De La Garza, Toledo Y Neffa (Comps) Clacso, Ceil-Piette, Ed.Buenos Aires. Impreso.

Organización Internacional del Trabajo. (2011). Centro de Internacional de Formación de la OIT. "Economía social y solidaria: nuestro camino común hacia el Trabajo Decente" Documento de trabajo. Montreal, Canadá- disponible en: http://www.ilo.org/empent/units/cooperatives/WCMS_166369/lang Consultado $10 \mathrm{de}$ Mayo de 2012)

Organización Internacional del Trabajo. 2010). Centro Internacional de Formación de la OIT "La economía social y solidaria un entendimiento común" "En respaldo a la primera edición de la Academia sobre Economía Social y Solidaria, 2010, Turín, Italia. Disponible en: $\quad$ http://www.socialeconomy.eu.org/IMG/pdf/SSEA-Reader2010-Spanish.pdf (Consultado: 10 de mayo de 2012)

Organización Mundial de la Salud (2001) Clasificación Internacional de las funciones y la discapacidad. OMS. Santander. Ginebra. 
Rofman, A. (2010); "La economía solidaria y los desafíos actuales" en revista de ciencias sociales, segunda época, año 2, $N^{\circ} 18$, Bernal, Ed. Universidad Nacional de Quilmes, primavera pág.159 - 175

Vázquez, G. (2010) "El debate sobre la sostenibilidad de los emprendimientos asociativos de trabajadores autogestionados", en revista de ciencias Sociales, segunda época, año2, $N^{\circ}$ 18, Bernal, ed.: Universidad Nacional de Quilmes, primavera. pág; 97-120. 